\title{
Fibrolipomatous hamartoma of the digital branches of the median nerve
}

\author{
MM Hosain, ${ }^{1}$ MM Momen ${ }^{2}$, AKM F Haque ${ }^{3}$
}

\begin{abstract}
Fibrolipomatous Hamartoma is an idiopathic disorder which may be related to hypertrophy of mature fat cells and fibroblasts in the epineurium. It is a rare condition which most commonly affects the median nerve. Presentation is usually before 30 years of age.

Some of them are presented with signs and symptoms of nerve entrapment and some are associated with macrodactyly (macrodystrophia lipomatosa) with gross cosmetic abnormality. MRI can be an important preoperative diagnostic tool. Biopsy and histopathology report can confirm the pathology.

This report describes a case of Fibrolipomatous Hamartoma of the digital branches of left index and middle fingers of median nerve associated with macrodactyly. A 25-years-old male patient having this problem came to Apollo Hospitals Dhaka with an abnormally large left index and middle finger. Debulking by excision of the lipomatous tissue along the digital branches of median nerve was performed. Three weeks postoperatively, the patient had no major complaints and the mass decreased in size without any motor or functional losses. Sensory function also found to be near normal with a small area of numbness at the tip of the left index finger.
\end{abstract}

Key Words: Fibrolipomatous Hamartoma, Rare benign tumour, Macrodactyly, Digital branches of Median nerve.

Introduction: Fibrolipomatous Hamartoma is a rare benign tumour. The condition has also been designated as Fibrolipomatous nerve enlargement, Lipofibromatous Hamartoma, Lipofibroma, fibro fatty nerve enlargement and Neurolipoma. World Health Organization tumour classification describes Fibrolipomatous Hamartoma as lipomatosis of the nerves. A review of the literature showed only few cases of Fibrolipomatous Hamartoma. This rare condition most commonly affects the median nerve. Some times it may present with macrodactyly. MRI can be an important diagnostic tool. Treatment by surgery has some indications - multiple biopsies can be done to confirm the diagnosis, release of nerve entrapment if any, de-bulking - if gross cosmetic abnormality.

\section{Patient, Methods and Results}

A 25 years old man came to our plastic surgery out patient clinic with an enlarged left index and middle finger since his childhood. For the last 3 years it increased in size significantly. It was associated with paraesthesias of left index and middle finger. There was no history of trauma.

On examination, his general condition was good, all the vital parameters were normal. Local examination showed left index and middle fingers were exceptionally large and enormous.

Skin color was normal. There was no visible vein or pulsation or scar mark on the surface. Local temperature was not raised with normal capillary refill. Patient could move the fingers but some restriction of movement was noted at the distal interphalangeal joint of the left index finger. Sensations of the affected fingers were less than normal. The finger swelling was soft, non tender and non compressible similar to neurofibromatosis.
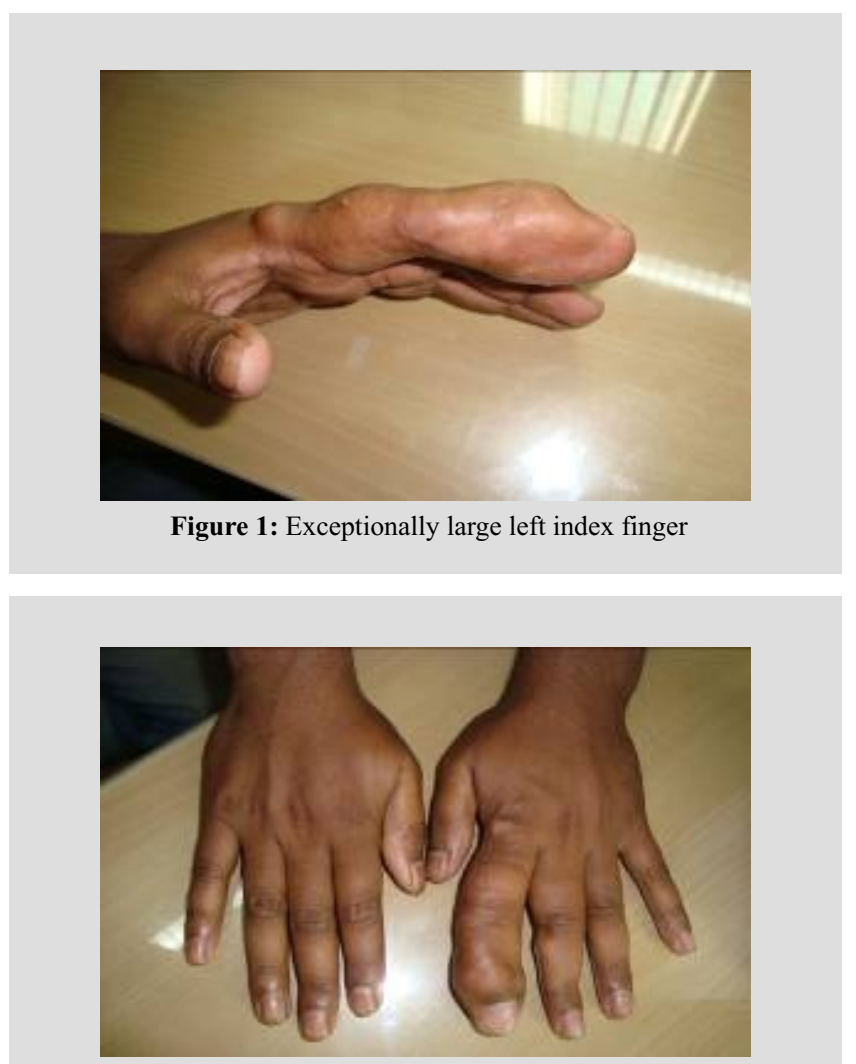

Figure 2: Macrodactyly of left index and middle finger with normal fingers in the right side.

Radiographic examination showed bony spur at the base of the distal phalanx of left index finger, the joints were normal. A soft tissue swelling involving the whole of the left index finger and some areas of left middle finger was noted. 


\section{Fibrolipomatous hamartoma}

Fine Needle Aspiration Cytology showed Benign Mesenchymal tumour.

Debulking of fingers was planned under tourniquet control. The proposed fingers were explored with Brunner's incisions with the aim to explore both the digital nerves of fingers.

After exploration, all the digital nerves of those two fingers were found enlarged and thickened with infiltrated lipomatous tissues. A diffuse yellowish lipomatous tissue was also found along and around the digital nerve fibers.

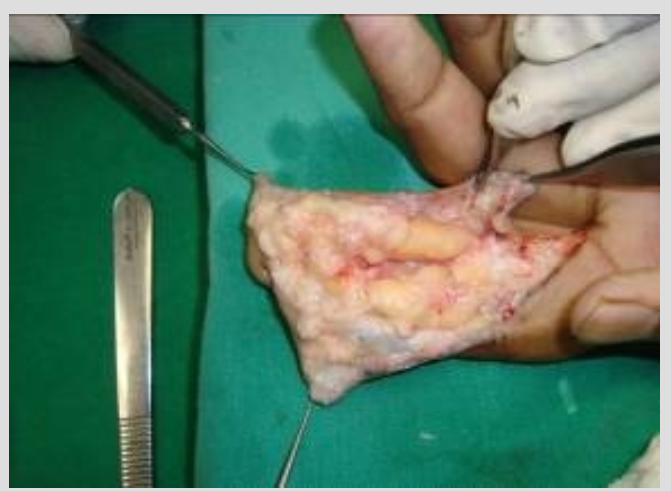

Figure 3: Yellowish lipomatous tissues in and around of both digital nerves of left index finger.

Under magnification, the lipomatous tissues were excised with preservation of the nerves. Bony exostosis also nibbled and removed. Haemostasis was secured. Skin closed with 5/0 prolene.

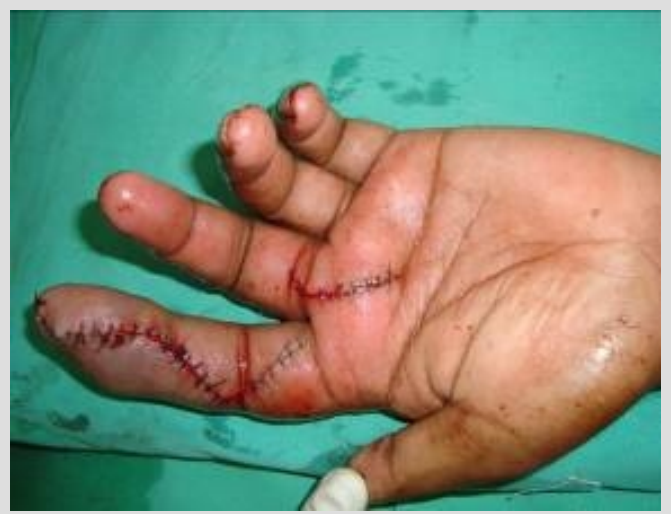

Figure 4: After closure of wounds

The histological sections of the lesion confirmed Fibrolipomatous Hamartoma with mature benign fibrofatty soft tissue.

On 12th post operative day the stitches were removed. After three weeks the wounds were healed. Patient could move his operated fingers. Sensation came back with a small area of numbness at the tip of the left index finger.

Discussion: Adipose tissue is a normal constituent of peripheral nerves which is usually located with in the perineurium and epineurium ${ }^{1}$. The intraneural lipomatous tumours are believed to arise from these normal adipose cells which are found infiltrating between the nerve bundles. It may also occur from nerve sheath. ${ }^{2}$ It most commonly occurs in the upper extremity of infants and children and usually affects the median nerve. ${ }^{3-5}$ In 1978, Terzis JK et al, classified benign fatty tumors of peripheral nerves in to three types; well capsulated intraneuronal lipomas, diffusely infiltrating fibrofatty tumors or Lipofibromatous Hamartoma and macrodystrophia lipomatosa which is a infiltrating fibrofatty lesion with associated focal macrodactyly. ${ }^{6}$

There are some significant differences between the well encapsulated and the diffusely infiltrative Fibrolipomatous Hamartoma types of intraneural lipomas. Average age at the time of appearance of well encapsulated type is 45 years with female predominance while the infiltrative type arises in a younger age group with no sexual predominance. ${ }^{7-8}$ Typically it presents in the 3rd to 4th decades of life with signs and symptoms of nerve compression in the distribution of the affected nerves. ${ }^{9}$ There is usually a long history of a painless mass since childhood. ${ }^{10,11}$ Patient may be aware of a painless mass for years. Patients may have signs and symptoms of nerve compression in the distribution of the affected nerve characterized by paraesthesia, motor deficit and pain. ${ }^{12,13}$ Patient may present with abnormally large finger(s) (macrodactyly). Bony abnormality may also occur. ${ }^{14}$

In our patient, painless masses in the left index and middle fingers were present since childhood. He came to us in his $3 \mathrm{rd}$ decade, with macrodactyly (left index and middle finger) and paraesthesia (predominantly hypoesthesia) with bony deformity at the distal phalanx of left index finger.

As with all neoplasm, the exact etiology of lipomata is unknown. ${ }^{8,15}$ Some researchers consider Fibrolipomatous Hamartoma to be congenital tumour, ${ }^{10}$ while others believe that it is incited to grow by nerve irritation, inflammation, or prior trauma. ${ }^{16}$ There is no familial predisposition. ${ }^{17}$ About $78-$ $96 \%$ of patients present with involvement of upper limb and there is a marked predilection for median nerve. ${ }^{17,18}$ More than $80 \%$ of Fibrolipomatous Hamartoma arises exclusively in the median nerve. ${ }^{10}$ Other nerves may also get involved - eg. ulnar nerve, radial nerve, axillary nerve, musculocuteneous nerve, brachial plexus, and cranial nerve. Nerves in the lower extremity can be affected in $4-22 \%$ of patients. In $27-67 \%$ of cases Fibrolipomatous Hamartoma is associated with macrodactyly (Macrodystrophia lipomatosa) ${ }^{17,18}$ where it mostly affects the index and middle finger. ${ }^{19,20}$ Histologically, perineural and endoneural fibrosis cause thickening of the neural fascicles. The interfascicular connective tissue is infiltrated by mature fat cells. ${ }^{10}$ In our case, mature fat cells were found in the excised tissues. The differential diagnoses 


\section{Fibrolipomatous hamartoma}

of the digital nerves masses include intraneuronal lipoma, neurofibromatosis and vascular malformation. The presence of mature fat within the nerve virtually excludes all other diagnostic considerations except for intraneural lipoma. In case of intraneural lipoma, the fat content arises from fatty tissue within the epineurium, so this condition will present as a focal mass separate from the neural fascicles, instead of infiltrating in between and separating the neural fascicles. MRI should readily differentiate between the two entities". MRI finding e.g. coaxial-cable-like appearance on axial planes and a spaghetti-like appearance on coronal planes of the lesion is often pathognomic and can allow a confident diagnosis, even without the need for biopsy. ${ }^{16}$ The treatment of Fibrolipomatous Hamartoma is controversial.

Conventional treatment involves carpal tunnel decompression (if needed) by excising the transverse carpal ligament, followed by biopsy of the enlarged nerve. ${ }^{21}$ This procedure has resulted in clinical improvement in $60 \%$ of patients in one study. ${ }^{22}$ Debulking of the tumor can also be done but may compromise the vascularity and that may affect neurological function. ${ }^{16}$ For complete resection, both satisfactory results and catastrophic motor and sensory deficit have been reported. ${ }^{10}$

Conclusion: In conclusion, Fibrolipomatous Hamartoma is a rare benign tumour that most commonly affects the median nerve. It may present with macrodactyly. In this case, it mainly affects the digital branches of left median nerve. Careful history and methodical examination is essential for its diagnosis. Local X-ray as well as MRI can help in accurate diagnosis. Final diagnosis can be achieved from histopathological reports. As the treatment is still controversial so, reports of such rare benign tumors need publication and the treatment protocol shared among the surgeons.

\section{References:}

1. Chatillon CE, Guiot MC, Jaques L. Lipomatous, vascular, and chondromatous benign tumors of the peripheral nerves: representative cases and review of the literature. Neurosurg Focus. 2007;22(6):E18.

2. . Friedlander HL, Rosenburg NJ, Graubard DJ. Intraneural lipoma of the median nerve. Report of two cases and review of literature. J Bone Joint Surg Am. 1969;51(2):352-362.
3. . Phalen GS, Kendrik JI, Rodriguez JM. Lipomas of the upper extremity: a series of fifteen tumors in the hand and wrist and six tumors causing nerve compression. Am J Surg. 1971; 121(3):298-306.

4. . Passaretti U, Messore L, Lanza F. A 2nd case of intraneural lipoma of the median nerve at the wrist (case reports). Chir Organi Mov. 1978;64(4):435-438

5. Matsuo T, Sugita T, Shimose S, Kubo T, Yasunaga Y, Ochi M. Intraneuronal lipoma of the posterior interosseous nerve. J Hand Surg (Am). 2007;32(10):1530-1532.

6. . Terzis JK, Daniel RK, Williams HB, Spencer PS. Benign fatty tumors of the peripheral nerves. Ann Plast Surg. 1978; 1(2):193-216.

7. . Bick EM. Lipoma of the extremities. Ann Surg. 1936;104(1):139-143.

8. Chiao HC, Marks KE, Bauer TW, Pflanze W. Intraneural lipoma of the sciatic nerve. Clin Orthop Relat Res. 1987;(221):267-271.

9. . So CK, Tam KF, Lui CY, Lee CM. Fibrolipomatous hamartoma of the Median Nerve. J HK Coll Radiol. 2007;10:81-84.

10. Cavalllaro MC, Taylor JA, Gorman JD, Haghighi P, Resnick D. Imaging findings in a patient with Fibrolipomatous hamartoma of the median nerve. AJR Am Roentgenol. 1993;161:837-838.

11. Toms AP, Anastakis D, Bleakney RR, Marshal TJ. Lipofibromatous hamartoma of the upper extremity: a review of radiologic findings for 15 patients. AJR Am J Roentgenol. 2006;186:805-811.

12. Canga A, Abascal F, Faustino Cerezal F, Bustamante M, Perez-Carro L, Vazquez-Barquero A. Fibrolipomatous hamartoma of the median nerve. J Neurosurg. 1998; 89:683.

13. Paulo JL, Marcos CL, Cláudia SKK, Carlos ES, Rosana HS, Lineu CW. Hamartoma fibrolipomatoso de nervo mediano (Fibrolipomatous Hamartoma of median nerve). Arc Neuropsiquiatr. 2005;63(3-B):881884.

14. Gang RK, Maklouf S. Macrodystrophia lipomatosa - case report. Chir Plastica. 1986;8:177-180.

15. Akisue T, Matsumoto K, Yamamoto T, Kizaki T, Fujita I, Yoshia S, Kurosaka M. Neural fibrolipoma of the superficial peroneal nerve in the ankle: a case report with immunohistochemical analysis. Pathol Int. 2002;52(11):730-733.

16. Marom EM, Helms CA, Fibrolipomatous hamartoma: pathognomic on MR imaging. Skeletal Radiol. 1999;28:260-264.

17. Silverman TA, Enzinger FM. Fibrolipomatous hamartoma of nerve: a clinicopathologic analysis of 26 cases. Am J Surg Pathol. 1985;9:7-14.

18. Amadio PC, Reiman HM, Dobyns JH. Lipofibromatous Hamartoma of nerve. J Hand Surg. 1988;13:67-75.

19. Kelikian H. Congenital deformities of the hand and forearm. Philadelphia: Saunders; 1974:610-635.

20. Broadwater BK, Major NM, Goldner RD, Layfield. Macrodystrophia lipomatosa with associated fibrolipomatous hamartoma of the median nerve. Pediatric Surgery. 2000;16:216-285

21. Giuliano V, Outwater EK, Mitchell DG, Bruke MA. Median nerve Hamartoma: MRI using chemical shift techniques. Magn Reson Imaging. 1997; 15:1091-1094.

22. Warhold LG, Urban MA, Bora FW Jr, Brooks JS, Peter SB Lipofibromatous hamartoma of the median nerve. J Hand Surg. 1993;18:1032-1037. 